\title{
Tratamento sistémico do cancro do pulmão duas décadas de progresso - Um ponto de vista pessoal...
}

\author{
Venceslau Hespanhol \\ Faculdade de Medicina do Porto \\ Centro Hospitalar e Universistário S. João - Serviço de Pneumologia
}

\section{INTRODUÇÃO}

Quando analisamos a evolução e o notável progresso dos tratamentos do carcinoma de não pequenas células do pulmão, avançado, ao longo dos últimos vinte anos, poderemos estabelecer dois períodos. Nos primeiros dez anos, assistimos a vários desenvolvimentos relativamente à otimização quimioterapia, novos fármacos (pemetrexed e bevacizumab), recuperação de um antigo conceito, a manutenção, novas estratégias terapêuticas, a "individualização" da quimioterapia, os primeiros passos em direção à medicina de precisão. A segunda década foi marcada pela consolidação do conceito medicina de precisão na oncologia pulmonar, o papel central da biologia molecular no diagnóstico e no estabelecimento de um novo elemento de decisão terapêutica, o biomarcador. Aúltima metade de segunda década é marcada por um tratamento há tanto tempo esperado e só agora concretizado, a Imunoterapia. Tudo isto, alterou definitivamente, a forma como sempre se olhou para o cancro do pulmão avançado, de doença rapidamente fatal, para uma realidade de doença crônica, com múltiplas opções terapêuticas, permitindo alterar definiti- vamente o prognóstico, para muitos doentes. Comecemos pelo princípio...

\section{A QUIMIOTERAPIA NO TRATAMENTO DO CANCRO DO PULMÃO AVANÇADO}

A Quimioterapia foi, a base do tratamento do carcinoma não pequenas células do pulmão (CNPC). Quando Joan A Schiller ${ }^{1}$ iniciou, em 1996, o recrutamento de um ensaio clínico, independente, em que comparava "head to head", várias associações de quimioterapia, contendo platino, em doentes em estádio IIIB (derrame pleural ou pericárdico maligno) ou IV, com CNP$\mathrm{CP}$, o cancro do pulmão já era uma das principais causas de mortalidade por cancro, representando um terço dessa mortalidade ${ }^{2}$. Embora, em 2002, quando este ensaio foi publicado, já fosse mais consensual, que o carcinoma de não pequenas células do pulmão avançado, beneficiava com tratamento sistémico antineoplásico, nem sempre foi assim. Durante décadas, questionou-se se faria sentido, tratar estes doentes ${ }^{3,4,5}$, aconselhando-se a utilização de quimioterapia, unicamente, num contexto de ensaio clínico, em 
face dos efeitos adversos e dos, muitas vezes dececionantes, resultados da resposta e sobrevivência ${ }^{1,3,4,5}$. Posteriormente, numa grande metanálise publicada em $1995^{6}$, foi possível, provar pela primeira vez, que quimioterapia associada a cuidados de suporte, era melhor que cuidados de suporte isoladamente, reduzindo o risco de morrer em 27\% (HR-0,73). É, fundamentalmente, a partir desta ${ }^{6}$, que o tratamento o cancro do pulmão avançado, inicia um caminho atingindo hoje, objetivos impossíveis de imaginar nessa altura. Era então assumido que a melhor opção de quimioterapia envolvia um composto de platino, de preferência cisplatino, associado a um ou dois outros antineoplásicos ${ }^{1,7,8}$, explorando a ideia sempre assumida em oncologia, no limite, maximizando a intensidade da dose, qualquer cancro pode ser destruído! ${ }^{9}$.

\section{DUPLETO OU TRIPLETO, COM OU SEM PLATINO E, QUANTOS CICLOS?}

As bases da quimioterapia, incluindo cisplatino, no cancro do pulmão, foram construídas com o conhecimento adquirido nos finais dos anos setenta, fundamentalmente, desenvolvido durante os anos oitenta e noventa do século passado ${ }^{1,2,3,7}$. A intensidade de dose da quimioterapia esteve sempre associada ao benefício terapêutico ${ }^{9}$, embora a evidência clínica relativamente ao cancro do pulmão, seja escassa, pois os seus preceitos, não foram testados em ensaios randomizado. Frequentemente, as orientações terapêuticas resultavam de inferências a partir de estudos "in vitro" ou, de estudos prospetivos e séries retrospetivas $^{10,11,12}$. Além da intensidade de dose, o número de fármacos a utilizar, nos esquemas de quimioterapia para tratamento do CNPCP também foi também procurado, na espectativa de elevar a taxa de resposta, quase sempre inferior aos $20 \%^{7}$. Esquemas de dois e três fármacos foram extensamente testados, tendo-se concluído que a associação ideal, deveria conter dois fármacos, sendo um deles, um composto de platino. ${ }^{13,14}$. No final, os resultados foram concordantes, a adição de um terceiro fármaco não adicionava benefício aos doentes ${ }^{14}$.

O equilíbrio entre intensidade terapêutica e tolerância dos doentes é fundamental para o êxito em oncologia pulmonar, fundamentalmente quando se trata de doença avançada. Além da intensidade de dose, do número de fármacos envolvidos, o número de ciclos sempre foi questionado ${ }^{15}$. Várias investigações mostraram que, prolongar a quimioterapia, para além de 3 a quatro ciclos de quimioterapia ${ }^{15,16}$, não determinava benefício na sobrevivência dos doentes.

\section{PEMETREXED NO ADENOCARCINOMA DO PULMÃO, "CUSTOMISING CHEMOTHERAPY" INDIVIDUALIZAÇÃO DA TERAPÊUTICA, "AS DUAS FACES DE JANUS"}

Quando, no 12th World Cancer Congress em 2007 , foi apresentada uma análise ${ }^{17}$ não planeada de um ensaio clínico, previamente publicado, em que se comparava docetaxel versus pemetrexed, em 2. ${ }^{a}$ linha, no tratamento do CNPC ${ }^{18}$, verificou-se que não era possível tratar da mesma forma todos os CNPC. Apesar de se tratar de uma análise retrospetiva, ficou claro que os doentes com carcinoma não escamoso do pulmão, respondiam muito melhor, quando tratados com Pemetrexed; ao invés, os escamosos, tinham melhor comportamento, quando tratados com Docetaxel. Este tipo de avaliação foi também realizada, num ensaio clínico publicado em 2009 por Giorgio Sca-

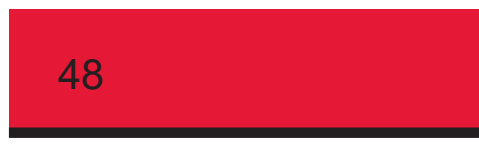


gliotti, que comparava, em primeira linha, cisplatino/pemetrexed com cisplatino/gemcitabina, em doentes com CNPC IIIB/IV20. O estudo atingiu o seu objetivo principal, mostrando, não inferioridade entre ambas as opções terapêuticas, no que respeita à sobrevivência mediana, tendo sido atingindo o valor de 10,3 meses para ambos os dupletos ${ }^{20}$. Porém, verificou que a sobrevivência era significativamente superior nos doentes com adenocarcinoma do pulmão, se tivessem sido tratados com cisplatino/pemetrexed (12,6 meses) em vez de cisplatino/gemcitabina (10,6 meses). O mesmo foi verificado para os carcinomas de grandes células, cuja sobrevivência foi de 10,4 meses, se tivessem sido tratados com cisplatino/ pemetrexed e de 6,7 meses, se a quimioterapia tivesse sido cisplatino/gemcitabina ${ }^{20}$. Apesar do objetivo primário deste estudo, não ter sido este, o seu principal contributo foi demonstrar que a classificação dos tumores em carcinomas de pequenas células e CNPC, se tinha tornado insuficiente. Era necessário, caracterizar o tipo de CNPC e, se se tratasse de um adenocarcinoma, ou outro, não escamoso, muito provavelmente, beneficiaria mais, se fosse tratado com um dupleto de platino e pemetrexed, que com qualquer outra associação ${ }^{20}$. Foi também a primeira vez que a sobrevivência mediana de um doente com CNPC metastático ultrapassou 1 ano, utilizando um dupleto com um platino, ganhando 5 meses aos 7,6 meses de sobrevivência mediana, dos doentes tratados com os dupletos testados por Schiller ${ }^{1}$. Até aqui, a escolha da quimioterapia, utilizada no CNPC, dependia mais do perfil de tolerância do doente e da experiência do médico, a partir desta observação, as características morfológicas do tumor passaram a definir o tratamento. Estas observações deram início à individualização terapêutica, baseada no conceito de preditor de resposta, quando se utiliza um deter- minado fármaco. Assim, o tipo celular da neoplasia, adenocarcinoma do pulmão, era preditor de melhor resposta e sobrevivência, se tratado com pemetrexed, o que não aconteceria, se tratasse de um carcinoma escamoso.

A procura de mecanismos de identificação dos determinantes da resposta aos tratamentos com quimioterapia foi particularmente intensa nos primeiros anos do século $21^{21,22,23}$. Os mecanismos mais estudados, são os relacionados com a reparação do ADN, crítico na manutenção da vida ${ }^{23}$. Duas enzimas, a "excison repair cross-complementation group 1" (ERCC1) e a "ribonucleotíde reductase M1" (RRM1), são especialmente importantes ${ }^{22,23}$. Quando o ADN é lesado, existem múltiplos mecanismos que de uma forma complementar, tentam evitar que persistam erros estruturais, no início à síntese de nova cadeia de $\mathrm{ADN}^{21,23}$. As proteínas enzimáticas envolvidas neste processo são muitas, destacam-se, porém, as ERCC1 e RRM1, a primeira pontificando, no processo de excisão do segmento de ADN lesado, e a segunda catalizando a síntese de ribonucleotídeos $^{21,23}$ fundamentais para o processo de reparação e substituição do ADN lesado e removido no processo anterior. A expressão destas proteínas, determinada por polimorfismos genéticos, parece, de alguma forma, influenciar a sua maior ou menor atividade no processo de recuperação do $A D N^{21}$. Em estudos realizados em doentes com cancro do pulmão, em estadio precoce, submetidos a cirurgia curativa ${ }^{24}$, foi demonstrado que a sobre expressão da ERCC1, era um preditor favorável de uma maior sobrevivência ${ }^{21,24}$. Por outro lado, a sobre expressão de ERCC1 e de RRM1, em doentes com cancro do pulmão avançado, era preditora de resistência respetivamente, aos platinos e à gemcitabina ${ }^{25}$, pois, a maior capacidade de corrigir lesões no ADN, induzidas pela quimioterapia, dificultava, que fosse iniciado o processo 
conducente à apoptose, inevitável, se essa capacidade regenerativa não existisse. Então, num contexto do cancro avançado, sob quimioterapia, a sobre-expressão ERCC1/RRM1 associa-se negativamente á sobrevivência ${ }^{25}$. Daqui resulta a analogia a Janus ${ }^{21}$, Deus Romano protetor das "entradas e saídas" (o que dá o nome ao mês de janeiro), que sendo único, tem duas faces, representando diferentes realidades, de acordo com o contexto em que nos encontremos ${ }^{23}$.

A análise retrospectiva do ensaio clínico de Hanna N \& col., publicado em 2004, dirigido aos doentes com CNPC do pulmão em 2. ${ }^{a}$ Linha ${ }^{18}$, comparando o "stand of care" docetaxel a um novo quimioterápico, o pemetrexed, previamente utilizado com algum êxito no mesotelioma pleural ${ }^{26}$, permitiu verificar que os doentes com carcinoma do pulmão não escamoso, em especial adenocarcinomas, beneficiavam significativamente, se fossem tratados com pemetrexed, ao invés, de docetaxel ${ }^{17}$. As razões prendem-se com o mesmo racional do ERCC1/RRM1. O pemetrexed é um antifolato, um sucedâneo do bem conhecido metotrexato. O seu alvo de ação são enzimas envolvidas na síntese dos folatos, em especial a timedilato sintetase (TS), a dihidrofolato redutase (DHFR) e glicinamida ribonucleotideo formiltransferase (GARFT) $)^{27,28}$. Genericamente os tumores escamosos, têm uma sobre expressão da TS, daqui resultando muito menor atividade do pemetrexed ${ }^{27,29}$. Pelo contrário, os doentes com adenocarcinoma do pulmão, em especial, os com sub-expressão da TS, quando se tratados com pemetrexed, mostram benefício, tanto no tempo livre de progressão, como na sobrevivência global $^{27,28,29}$. Ainda hoje, a escolha do tratamento de um doente com carcinoma não escamoso, em estadio IV, sem outra opção terapêutica que não quimioterapia, recai, grande parte das vezes, num dupleto com platino e pemetrexed.

\section{ANTI-ANGIOGÉNESE CANCRO, A REALIDADE AINDA INCOMPLETAMENTE COMPREENDIDA}

Após longos anos de investigação, Judah Folkman $^{30}$, desenvolveu as bases científicas da neovascularização (angiogénese) tumoral e uma nova perspetiva surgiu, no tratamento dos tumores. As suas investigações publicadas, inicialmente nos "Seminars in Medicine Of The Beth Israel Hospital, Boston" e posteriormente, em 1971, publicadas no N Engl Journal Medicine, só, muito mais tarde, foram entendidas! ${ }^{31}$. A descoberta dos mecanismos da angiogénese tumoral e dos fatores que a estimulam ou a promovem, a identificação do "tumor angiogenic factor" (TAF), posteriormente designado, "vascular endotelial growing factor" (VEGF), criou enorme expectativa pela possibilidade de, comprometendo o acesso do tumor ao oxigénio e nutrientes, pudesse controlar o seu crescimento $^{31,32}$. Estes conhecimentossó foram publicados, mais de 20 anos depois?! $!^{32,33,34,35,36}$. Um dos conhecimentos mais interessantes, dirigia-se à forma como se estabelecia a angiogenese tumoral, tendo sido observado, que até determinada altura do seu desenvolvimento, os tumores sobrevivem unicamente por "difusão", criando, à medida que evoluem, um sistema de perfusão que permita o seu desenvolvimento ${ }^{31}$. Atualmente, a angiogénese tumoral, é uma das "Hallmarks of Cancer", tendo, a sua inibição, sido amplamente reconhecida, como um tratamento de valor para vários cancros, incluindo o cancro do pulmão ${ }^{32,33,34,35}$. Vários fármacos dos quais se destacam o Bevacizumab e o Nintedanib, inibindo o estímulo angiogénico do VEGF, têm em associação com quimioterapia sido utilizados ${ }^{32,33,34,35,36,37}$. O Bevacizumab, anticorpo monoclonal humanizado que atua ligando-se e inativando todas as isoformas do VEGF, bloqueando a angiogénese. 
Sandler e colaboradores ${ }^{33}$, estudaram 850 doentes com cancro do pulmão avançado de histologia não escamosa tratados com carboplatino e paclitaxel e randomizados para receber ou não bevacizumab. O grupo tratado com adição de bevacizumab à quimioterapia obteve uma sobrevivência mediana, pela primeira vez no cancro do pulmão avançado, superior a um ano, 12,3 meses $^{33}$, muito distante dos 7,5 meses observados por Shiller e colaboradores (embora aqui tivessem sido incluídos todos os CNPC), utilizando carboplatino e paclitaxel ${ }^{1}$. Foi como conseguir passar uma barreira psicológica!

Outros estudos, utilizando diferentes combinações, demonstraram que a adição de bevacizumab, numa primeira linha de tratamento, em doentes com cancro do pulmão de histologia não escamosa, beneficiavam, melhorando o tempo livre de progressão e a taxa de resposta ${ }^{34}$, relativamente à quimioterapia isolada. Estes resultados não foram, contudo, universalmente aceites, não sendo possível, em Portugal, a utilização deste fármaco, para esta indicação.

Outro dos antiangiogénicos, o Nintedanib, foi testado em 2. ${ }^{a}$ linha associados ao docetaxel e posteriormente ao pemetrexed, tendo demonstrado prolongar a sobrevivência e melhorar a qualidade de vida, sendo hoje, para a sua indicação, um tratamento disponível em 2. ${ }^{a}$ Linha em associação com o decetaxe $\left.\right|^{36,36}$.

\section{PEMETREXED, MANUTENÇÃO COM QUIMIOTERAPIA}

A introdução dos dupletos de quimioterapia platino+pemetrexed ${ }^{20}$ ou tripletos incluindo platino+paclitaxel ou Gemcitabina adicionados de bevacizumab $(32,33,34)$ permitiram adicionar um pouco mais de 5 meses à sobrevivência me- diana dos doentes com CNPC, não escamoso. O tratamento padrão utilizado envolvia um dupleto contendo platino, sendo previsível obter 20 a $40 \%$ de taxa de resposta e sobrevivência de cerca de um ano (7-12 meses $)^{20}$. No sentido de verificar se, nos doentes com CNPC do pulmão não escamoso, em que foi atingido o controlo da doença, seria possível aumentar o tempo livre de progressão e a sobrevivência global, foram realizados vários ensaios clínicos em que se pretendeu testar esta hipótese $e^{37,38,39}$. Depois de se ter verificado aumento do tempo livre de progressão e da sobrevivência como resultado do tratamento com pemetrexed em regime de manutenção, até progressão da doença ${ }^{37}$, novo ensaio o PARAMOUNT foi realizado, com o objetivo de definir de forma definitiva esta estratégia tratamento, em doentes com doença controlada ${ }^{38,39}$. O resultado final, mostrou claro benefício desta estratégia, alcançando-se pela primeira vez uma sobrevivência mediana superior a 14 meses $^{39}$. Infelizmente, só os doentes com histologia não escamosa beneficiaram com esta estratégia ${ }^{39}$, situação que se veio a pronunciar, de forma crescente. desde esta altura. Todos estes estudos permitiram provar que existe uma diferenciação clara entre os vários tipos celulares que integram a antiga denominação CNPC, em face das opções terapêuticas e resultado clínicos obtidos. Estes resultados, são ainda, uma das bases das decisões terapêuticas ainda hoje em utilização, para doentes, sem outras opções terapêuticas, que quimioterapia.

\section{O FATOR DE CRESCIMENTO EPIDÉRMICO "EGF"}

Desde a sua identificação no início dos anos 50 por Cohen e col..$^{42}$, a partir das glândulas sub-maxilares do rato, que foram desde logo identifi- 
cadas algumas as suas características, o seu recetor (EGFR) recetor da tirosinaquinase e vários membros da sua família ${ }^{42}$. A sobre expressão deste recetor transmembranar foi durante anos considerada associada ao desenvolvimento de tumores ${ }^{43}$, estando presente em mais de $62 \%$ dos CNPC, associando-se de forma significativa com o prognóstico da doença ${ }^{43}$. O EGFR medeia o crescimento celular, proliferação, invasão, metastização e promove a inibição da apoptose ${ }^{44,45}$. A inibição do recetor das tirosinaquinases foi testada em dois ensaios de fase 2 que mostraram ${ }^{44,45}$ tendo mostrado atividade significativa do gefitinib, em doentes com CNPC avançado, que levou à sua rápida aprovação $0^{46,47}$. Foram realizados dois ensaios de fase III, onde foi adicionado Gefitinib à quimioterapia, num dos casos cisplatino/gemcitabina, noutro carboplatino/paclitaxel e comparados com quimioterapia isolada. Os resultados foram desoladores, não havendo qualquer benefício da associação, contrariamente às expectativas ${ }^{48,49}$. Outra molécula, com mecanismo de ação e atividade semelhante, o Erlotinib, foi também testado em associação com a quimioterapia, tenod os resultados sido semelhantes ${ }^{50,51}$. Todos estes ensaios, envolvendo o Gefitinib e o Erlotinib, foram testados em doentes com CNPC e sem qualquer seleção significativa, pois associava-se a atividade dos fármacos com o númeor de copias do gene do EGFR e por conseguinte à sua expressão ${ }^{42,43}$. Neste mesmo ano, 2004, Thomas Lynch and col. ${ }^{52}$, estudando as características clínicas e moleculares de doentes que responderam ao gefitinib, doentes que nãso responderam e doentes que não foram tratados com gefitinib ${ }^{52}$. Verificaram que nos era possível identificar mutações somáticas nos exões 19 e 21 do EGFR ${ }^{52}$, tendo concluído que a resposta ao tratamento dependia da identificação destas mutações nos tumores ${ }^{52}$. Porém, apesar destes resultados, só vários anos depois, a existência destas mutações seria reconhecida, a nível global como o primeiro biomarcador realmente relevante no cancro do pulmão.

\section{ERLOTINIB EM DOENTES COM CNPC, PREVIAMENTE TRATADOS (BR.21)}

Apesar de já ter sido demonstrada a relação entre a resposta ao gefitinib e a identificação de mutações nos exões 19 (Del746-A750) e 21 (mutação pontual L858R) do EGFR ${ }^{52}$, muitos investigadores continuaram a relacionar a resposta ao tratamento com número de cópias do gene do EGFR e desta forma a sua expressão (46-50). Em 2005, Frances Shepherd ${ }^{53}$ onde provou que nos doentes já tratados com um dupleto de platino em 1. ${ }^{a}$ Linha, ou mesmo, após uma segunda linha de quimioterapia, mantendo performance status (PS) 0-3, o tratamento utilizando Erlotinib, prolongava a sobrevivência ${ }^{53}$. Foi a primeira vez que, de uma forma generalizada, em todo o mundo, se utilizou Erlotinib, com excelentes resultados, num pequeno número de doentes, ganhando a todas as alternativas, então possíveis, em relação à tolerância ${ }^{53}$. Esta opção de tratamento com Erlotinib, manteve-se ao longo dos anos, até que a relação mutações resposta ao tratamento se tornou inquestionável e se transformou em tratamento padrão cinco anos depois, após publicação de um ensaio clínico que tudo clarificou ${ }^{54}$.

\section{A INDIVIDUALIZAÇÃO DA TERAPÊUTICA, NO CANCRO DO PULMÃO - O EGFR}

Desde há várias décadas que era reconhecida a importância do EGFR no desenvolvimento dos tumores ${ }^{43,44}$, nomeadamente na génese de um sinal proliferativo celular, facilitação da metasti-

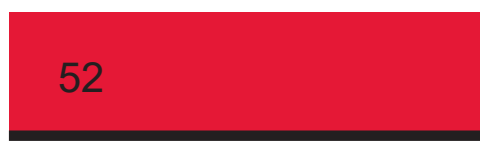


zação, angiogénese, inibição da apoptose $\mathrm{e}^{42-44}$ Fazia sentido que a inibição do processo gerador desse sinal pudesse ser utilizada no tratamento dos tumores, porém, mantinha-se a discussão sobre, em que doentes, mais beneficiassem dos potenciais fármacos inibidores do sinal proliferativo ${ }^{43,44,45}$. Esta discussão manteve-se, durante vários anos, apesar de, em 2004, Lynch e col. ${ }^{52}$, na sua série clínica, tivessem demonstrado que, a resposta ao tratamento ao gefitinib, estava ligada à identificação nas células tumorais com mutações específicas no gene do EGFR ${ }^{52}$.

Em 2009, Tony Mok e col. ${ }^{54}$. Publicaram um ensaio clínico, o Iressa Pan-Asia Study (IPASS) ${ }^{54}$ que definitivamente, alterou toda a base de decisão terapêutica, relativamente aos inibidores das tirosinaquinases ${ }^{54}$. Na altura em que o ensaio é desenhado, já existia uma clara convicção entre muitos investigadores, que grupos especiais de doentes ${ }^{52}$ beneficiavam mais que outros. Era claro que, adenocarcinomas, não fumadores, doentes do género feminino ${ }^{52}$, tinham mais tendência a responder ao tratamento, respondiam rapidamente e mantinham a resposta, muitas vezes, por períodos superiores a um ano ${ }^{52}$. Os critérios de seleção do IPASS, incluíam carcinomas não pequenas células do pulmão, com características de adenocarcinoma (incluindo carcinoma broncoalveolar), não fumadores, fumadores com menos de 10 unidades/maço/ano ou ex-fumadores, há pelo menos 15 anos, ainda não submetidos a tratamentos para o cancro do pulmão e não submetidos, por qualquer outra razão, a tratamentos biológicos e/ou imunológicos) ${ }^{54}$. Os doentes foram aleatoriazdos para receber o dupleto de quimioterapia ou gegitinib. O objetivo primário era o tempo livre de progressão (PFS) ${ }^{54}$. Após os primeiros 5 meses, em que o dupleto de quimioterapia tem melhor comportamento. Ou seja, em que a probabilidade do evento de interesse ocor- rer (progressão da doença) é menor nos doentes sob quimioterapia (hazard ratio), que nos doentes tratados com gefitinib, dando-se a inversão da tendência inicial ${ }^{54}$. Esta tendência de melhor comportamento dos doentes sob gefitinib, mantém-se até ao final da avaliação e, avaliadas posteriormente as mutações do EGFR, verificou-se que havia uma associação clara entre doentes EGFR+ e o seu comportamento sob gefitinib ${ }^{42}$. Embora a conclusão geral tenha sido que gefitinib foi superior ao dupleto de carboplatino mais paclitaxel neste grupo de doentes ${ }^{42}$, o que se transformou em "case-study", foi definitivamente ficar provado que existia uma relação clara entre mutações do EGFR e tempo livre de progressão $0^{42}$. Isto foi possível por dois motivos: primeiro, grande parte dos doentes realizaram pesquisa das mutações do EGFR; segundo: elevada prevalência de EGFR+ na amostra avaliável para estudo molecular $(59,7 \%)$, que permitiu, com facilidade, identificar a associação entre GFR+, resposta ao gefitinib e e tempo livre de progressão aumentado ${ }^{42}$.

Após este estudo, vários foram publicados nos anos subsequentes desenhados unicamente para doentes com EGFR+ em que se comparava dupleto de quimioterapia com um inibidor das tirosinaquinases, gefitinib, erlotinib e mais posteriormente, afatinib ${ }^{55,56,57}$. Em todos estes estudos ficou provado, pela taxa de resposta e pela PFS, que os doentes com EGFR+, têm um enorme benefício se forem tratados com inibidores das tirosinaquinases, em primeira linha ${ }^{55,56,57}$. Posteriormente, mesmo em relação à sobrevivência global, apesar das dificuldades de análise devido à possibilidade de aceder ao tratamento investigacional, uma vez tendo-se verificado progressão sob o tratamento padrão ("crossover"), foram atingidos valores impensáveis pouco tempo antes ${ }^{55,58,59}$, ultrapassando os dois anos, quando pouco tempo antes, eram inferiores a um ano. 


\section{ALVOS MOLECULARES NO CANCRO DO PULMÃO - OS BIOMARCADORES}

A metodologia subjacente ao desenvolvimento das mutações do EGFR como alvos terapêuticos, determinaram enorme interesse no que respeita à procura de outras mutações ativadoras da oncogénese dos cancros do pulmão. Formaram-se consórcios nacionais e internacionais para identificação de mutações oncogénicas, foi melhorada a tecnologia, permitindo analisar múltiplas mutações simultaneamente e a partir daí, desenvolverem inibidores mantendo a metodologia de desenvolvimento seguida em relação ao EGFR ${ }^{60,61}$. Foram identificadas mutações condutoras do sinal proliferativo, sendo as mais frequentes as identificadas nos genes KRAS, NRAS, EGFR, BRAF, MET, HER2, PIK3CA, ALK, RAF1 e fusões nos genes RET, ALK, ROS1, NTRK. As mutações mais frequentes são as do KRAS/ NRAS, que correspondem a 15 a $25 \%$ das mutações encontradas nos adenocarcinomas do pulmão $0^{60}$, ainda atualmente sem que exista um inibidor aprovado, mas com múltiplos ensaios atualmente em curso, advinha-se que num futuro próximo será identificado inibidor ${ }^{60,62}$. Os principais alvos moleculares que foram identificados e para os quais já existem inibidores conhecidos são o EML4-ALK, ROS1, BRAF, HER2, MET, NTRK. A prevalência destas mutações é desigual $^{60,62}$, porém, a sua inibição tem permitido alterar completamente a história natural da doença, aumentando a sobrevivência e melhorando de forma significativa a qualidade de vida destes doentes ${ }^{60,62}$. A inibição do sinal oncogénico gerado pela fusão do EML4-ALK foi, o tratamento molecular que se seguiu ao do EGFR, tendo sido demonstrado que nos doentes com translocação do ALK, o Crizotinib foi superior ao tratamento com dupleto de quimioterapia padrão ${ }^{63}$, no tempo livre de progressão, à taxa de resposta e à probabilidade de sobreviver um ano, respetivamente, 11 versus 7,0 meses, $75 \%$ versus $45 \%$ e $84 \%$ versus $79 \%{ }^{63}$. Quase simultaneamente este inibidor provou ser ativo para na translocação do ROS1, sendo obtidos excelentes resultados: $72 \%$ de respostas e 19,2 meses de tempo livre de progressão ${ }^{53}$. Dada a sua atividade pan-inibidor das tirosinaquinases ${ }^{63,64}$ o Crizotinib é ativo nas translocações ALK e ROS1 e possui igualmente capacidade de bloquear o sinal induzido pela mutação no exão 14 do gene MET ${ }^{65}$. Outa mutações, nos genes B-RAF, HER-2, RET, NTRK, com menor frequência, tendo inibidor específico e mostrando resultados aceitáveis ${ }^{66}$, ainda que, nem sempre aprovadas e disponíveis ${ }^{67}$.

O fator comum a todos estes tratamentos, é a necessidade de estar presente uma característica molecular do tumor, para que se verifique o benefício terapêutico. Daqui a noção de biomarcador está presente sempre que surge a necessidade de decisão terapêutica, desde a identificação da histologia, escamoso ou não escamoso, como relativamente à alteração molecular identificável, no tumor. Sem estas informações não é possível antecipar o benefício do doente impossibilitando a decisão terapêutica ${ }^{68}$.

\section{TRAÇOS CARACTERÍSTICOS DO CANCRO, HETEROGENEIDADE E RESISTÊNCIA TUMORAL AOS TRATAMENTOS}

Ao longo desta "viagem" é clara uma clara evolução de conceitos no que se refere ao processo neoplásico. Inicialmente, a proliferação celular, a destruição do tumor era a única preocupação. Encontrar citotóxicos, definir intensidade de dose, tendo em contaa tolerância. Poste-

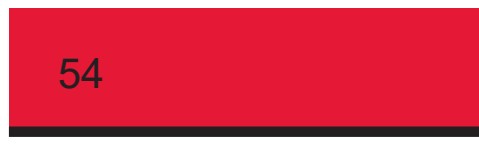


riormente, olhar também para as características do hospedeiro, com o conceito da personalização do tratamento inicialmente estudando polimorfismos e a sua influência na atividade dos citotóxi$\cos$. A estratégia da destruição direta das células tumorais, raramente foi coroada de êxito. No ano 2000, Hanahan e Weinberg, propuseram seis capacidades adquiridas pelas células tumorais durante o processo de desenvolvimento tumoral $^{69}$. Estas capacidades biológicas dos tumores, são elementos de um processo progressivo que se vai desenvolvendo até causar a disrupção anatómica e funcional do(s) órgão(s) onde se desenvolveu. Esta"pegada" biológica incluía as capacidades: sinal proliferativo permanente, insensibilidade aos fatores supressores do crescimento, resistência à apoptose, multiplicação celular permanente, indução da angiogénese, capacidade de invasão e metastização de outros órgãos. A instabilidade genómica (levando à heterogeneidade clonal) e a inflamação promovem todas as referidas capacidades ${ }^{69}$. Em 2011, os mesmos investigadores ${ }^{70}$ adicionavam a estas peculiaridades do cancro, outras ainda mais difíceis de controlar: reprogramação do metabolismo energético celular, libertar-se da destruição pela imunidade e recrutar células normais, contribuindo tudo em conjunto para a criação de uma área com características físicas, químicas e biológicas independentes, o microambiente tumoral ${ }^{70}$. Todas estas características ligadas ao desenvolvimento tumoral, estão na génese da heterogeneidade clonal tumoral ${ }^{71}$, estão na génese da constatação, que na clínica diária todos reconhecemos:" independentemente da resposta ao tratamento, da duração do tempo livre de progressão, mais tarde ao mais cedo, o tumor irá progredir. Este desafio permanente tem vindo a impulsionar o desenvolvimento de novas opções terapêuticas com a finalidade de manter o tumor sob controlo e/ou, encontrar novas opções de tratamento de $1 .^{a}$ linha.

\section{a. Inibidores do EGFR}

Após o sucesso dos inibidores das tirosinaquinases de primeira geração ${ }^{55,56}$ e posteriormente, segunda geração ${ }^{59}$ aumentado a resposta, o tempo livre de doença e a sobrevivência, surge a progressão da doença, entre 9-12 meses ${ }^{56,73}$. Múltiplas estratégias, foram tentadas para manter a resposta e os benefícios do tratamento, mantendo-o, se estivesse clinicamente ${ }^{74}$. Terapêuticas locais, nos casos de progressão oligometastática ${ }^{75}$. Porém, a indução terapêutica e a instabilidade genética tumoral, originaram novas mutações, acabando por surgir clones resistentes ao tratamento em curso ${ }^{76}$. Só uma nova inibição poderia controlar a doença e a qualidade de vida do doente ${ }^{77}$. Era necessário identificar as mutações de resistência e criar inibidores, para bloquear o crescimento tumoral. A mutação T790m é a mutação de resistência que mais frequentemente causa progressão em doentes sob tratamento com inibidores das tirosinaquinases de $1 .^{a}$ e $2 .^{a}$ geração ${ }^{76}$. Vários ensaios, inicialmente em segunda linha ${ }^{78}$ após progressão da doença e identificada a mutação de resistência $7790 \mathrm{~m}$, mostraram benefício adicionando mais 11 meses ao tempo livre de progressão. Posteriormente, em primeira linha ${ }^{79}$, para tratamento dos doentes com mutações EGFR+, foram obtidos resultados nunca antes atingidos, um tempo livre de progressão de quase 19 meses e uma sobrevivência global de 38,6 meses $^{79}$. Tal como acontece após os inibidores de primeira linha, após tratamento com osimertinib, surge de novo progressão da doença ${ }^{80}$, situação atualmente ainda não resolvida. 


\section{b. Inibidores do ALK}

Após os resultados extraordinários surgidos na sequência do tratamento com Crizotinib, muito se avançou no tratamento dos doentes ALK $++^{82,83}$. Cerca de 3 a $5 \%$ dos CNPCP têm fusão do ALK ${ }^{83}$. Depois da progressão sob crizotinib, devido ao desenvolvimento de mutações, má penetração no sistema nervoso central ou intolerância, outras opções terapêuticas utilizando, o ceratinib ${ }^{84}$, alectinib $^{85,86}$ e brigatinib ${ }^{87,88}$, demonstraram valor no prolongamento do tempo livre de progressão e globalmente da sobrevivência destes doentes. Posteriormente, testados em primeira linha versus crizotinib, o ceratinib, alectinib e o brigatinib mostraram acentuado benefício $84,85,86,87,88$, tanto no que concerne ao tempo livre de progressão, controlo da doença envolvendo o sistema nervoso central, sendo que o alactinib é, e provavelmente, proximamente, o brigatinib também, tratamentos padrão, na primeira linha terapêutica dos doentes ALK+. Os inibidores de segunda geração aumentaram, em muito, o tempo livre de doença, tanto em após falência do crizotinib, mas fundamentalmente quando utilizados em 1 . $^{\mathrm{a}}$ linha ${ }^{83,84,85,86,87,88}$, onde os valores medianos do tempo livre de progressão, são muito superiores a dois anos. Contudo, acaba por surgir progressão ${ }^{89} \mathrm{em}$ grande parte pelo aparecimento de novas mutações que determinam o surgimento de novos clones celulares resistentes a estas terapêuticas. O perfil mutacional dos clones celulares resistentes é diferente conforme o inibidor utilizado, conforme de primeira geração, ou segunda geração ${ }^{89}$, sendo que nesta situação o perfil mutacional é mais complexo e difícil de tratar. A mutação ALK G1202R é a mais frequente ${ }^{89} \mathrm{e}$ a sua importância advém do facto dos clones celulares que apossuem só poderem ser tratados com um novo inibidor do ALK o Lorlatinib ${ }^{90}$. Nos estudos reali- zados, utilizando biopsias seriadas de doentes submetidos a inibidores do ALK, verifica-se que a complexidade mutacional pós tratamento vai depender da variante ${ }^{91}$ e do inibidor utilizado ${ }^{89}$. Nalguns casos, outros mecanismos de resistência, amplificação de genes e processos de transição epitélio mesenquimatosa, determinam, até ao momento qualquer opção válida de tratamento destes doentes ${ }^{89,91}$.

\section{c. Imunoterapia}

Um dos "traços característicos" das células tumorais é a sua capacidade de fugir ao controlo imunitário. James Alison ${ }^{92}$, após ao longo dos anos 80-90 terem sido conhecidos mecanismos associados à função dos linfócitos $\mathrm{T}$, propôs a hipótese destas células imunitárias poderem destruir as células tumorais se fossem bloqueados os reguladores negativos que controlam a resposta imune (Immune Check Points) e que impedem o aparecimento de fenômenos de auto-imunidade ${ }^{92}$. O melhor conhecimento dos mecanismos envolvidos ${ }^{93,94}$ no funcionamento imunitário, permitiu identificar dois tempos na resposta imunitária adaptativa ${ }^{93}$. Por um lado, o processo de ativação linfocitária, que usualmente acontece ao nível dos gânglios linfáticos ${ }^{94,94}$ cujo regulador melhor estudado, foi o antigénio 4 do linfócito T (CTLA4), por outro, as proteínas bloqueadoras da resposta imune adaptativa ao nível tecidular, a proteína de morte celular programada 1 e o seu ligando (PD1/PDL1), permitiram concluir que, se essas proteínas pudessem ser bloqueadas, seria possível aumentar a eficiência imunológica anti-tumoral, ainda que, com risco acrescido de auto-imunidade ${ }^{94}$. $O$ conhecimento dos mecanismos funcionais associados à atuação da imunidade adaptativa, bem como, a cons-

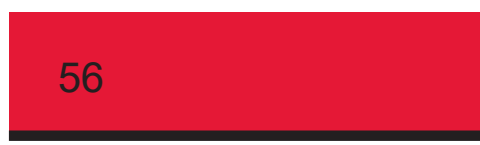


tatação que existia alguma entre o teor da proteina PDL1 nos tecidos e células imunes e a resposta a eficiência dos bloqueadores do PD1/ PDL1 ${ }^{94}$. É esta a base de todo um desenvolvimento meteórico de inibidores do "imunocheckpoint” (ICP) e da sua aplicação clínica. Inicialmente, em segunda linha terapêutica ${ }^{95,96,97}$ em comparação com o docetaxel. Posteriormente, em primeira linha, quando a marcação da PDL1 $1250 \%{ }^{98}$. O conhecimento foi rapidamente evoluindo, a tentativa de identificar marcadores de resposta aos inibidores do ICP foi amplamente estudada. A associação entre a marcação por imuno-histoquimica de PDL1 no tumor e células linfoides e a resposta aos ICP foi muito procura$\mathrm{da}^{95,96,97,98}$. Por outro lado, a proporção de mutações no tecido tumoral (TMB), como marcador de maior estímulo à resposta imune, foi também investigada como marcador ${ }^{99}$. A possibilidade real, de um tumor com um elevado teor de mutações, ter uma maior proporção de mutações não sinónimas, tornando-se, o tecido tumoral, menos semelhante ao tecido normal, o que elevaria a probabilidade ser reconhecido, pela imunidade como "não self" e mais facilmente destruído, especialmente se os controlos de resposta imunitária fossem reduzidos com os $\mathrm{ICP}^{99}$. Por outro lado, a carga tumoral, também foi investigada $^{100,101}$, sendo que, cada vez ficou mais claro, que o êxito com os ICP, também depende deste parâmetro. Daqui resulta o racional para as associações de ICP com quimioterapia ${ }^{102}$, com imunoterapia ${ }^{103}$ e com quimioterapia e antiangiogénicos ${ }^{104}$ que foram testadas, globalmente com êxito. De tudo isto resultou que uma destas opções terapêuticas, a associação ICP mais quimioterapia, esteja atualmente aprovada em muitos países, como tratamento padrão dos doentes com CNPC estadio IV, com bom estado geral e sem mutações ativadoras identificadas.

\section{NOTAS FINAIS}

Ao longo desta "viagem" de vinte anos ( $\mathrm{Fi}-$ guras $1,2,3)$, pela evolução do tratamento e do prognóstico dos doentes com CNPC do pulmão, ressalta, para além da enorme melhoria nos tratamentos e seus resultados na quantidade e qualidade de vida, a enorme diversidade biológica dos tumores e como isso influencia o resultado final, dos tratamentos disponíveis para os doentes. Os tumores avançados, por definição, são, por definição, clonalmente heterogéneos, como resultado das soluções moleculares que encontram para sobreviver. À medida que um tumor evolui, mesmo sem tratamento, vai-se modificando biologicamente por este motivo. As intervenções terapêuticas disponíveis, aceleram essas modificações, resultando, no final, no aparecimento de clones celulares que resistem às opções terapêuticas disponíveis. Apesar disto, cada vez quetratamos um doente com cancro do pulmão avançado, o facto de reduzirmos a carga tumoral, bloquearmos o seu desenvolvimento, mesmo de forma provisória, permite aumentar a sobrevivência e fundamentalmente a qualidade de vida, que a progressão da doença maligna, usualmente compromete. Contudo, os bons resultados obtidos, aqui descritos, não são iguais para todos, utilizando um aforismo, muito conhecido em medicina, não há doenças, há doentes!... cada vez percebemos melhor, porque há doentes?! A identificação dos processos biológicos, a sua dinâmica, a interação molecular que constitui a vida em todas as suas formas, permite-nos perceber, que também na doença existe um caminho muito pessoal, muito dinâmico e em mutação permanente, cujos contornos não conseguimos muitas vezes compreender em toda a sua amplitude. 


\section{Venceslau Hespanhol}

Figura 1. Evolução da Taxa de Resposta 2000-2020

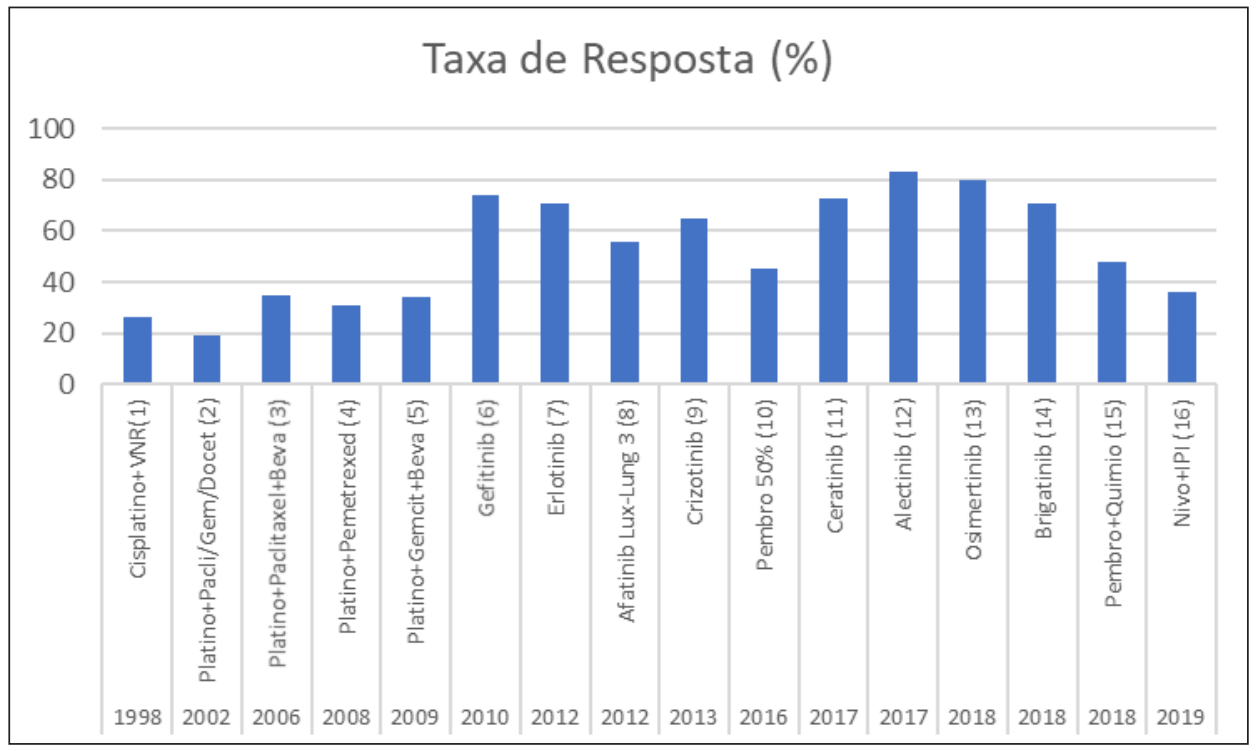

Figura 2. Evolução do Tempo Livre de Progressão 2000-2020

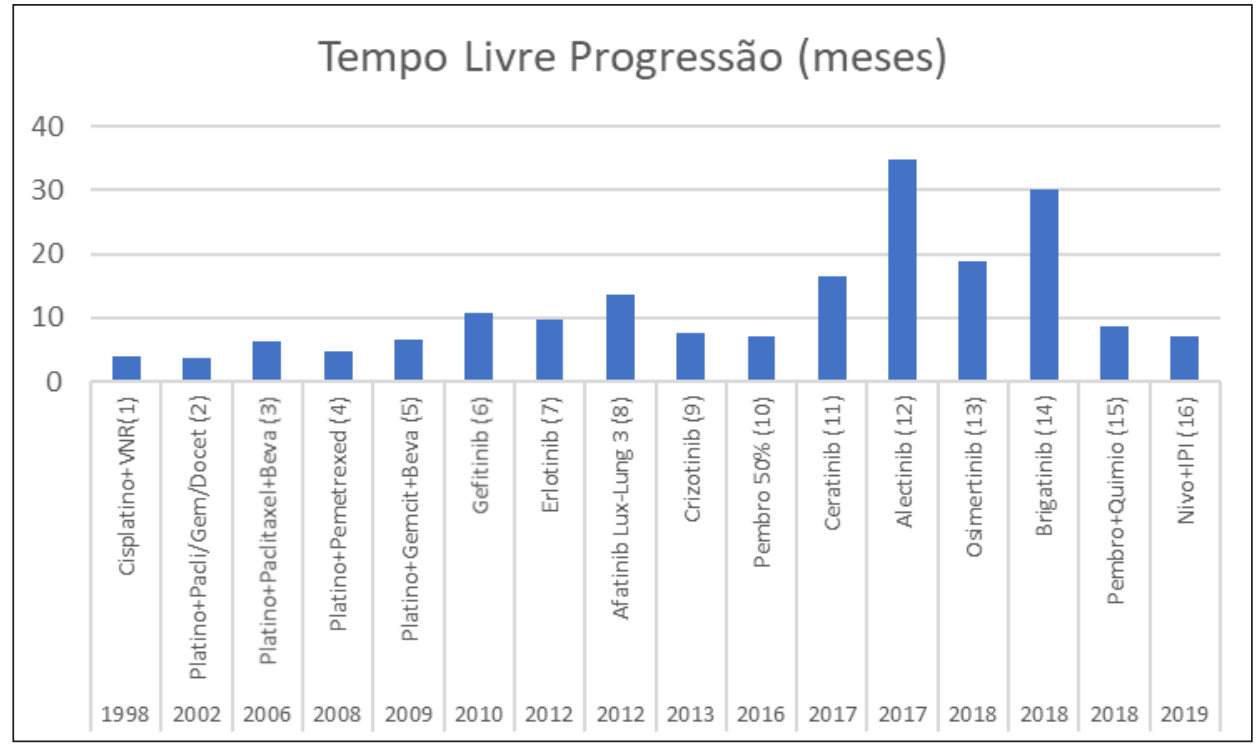


Figura 3. Evolução da Sobrevivência 2000-2020

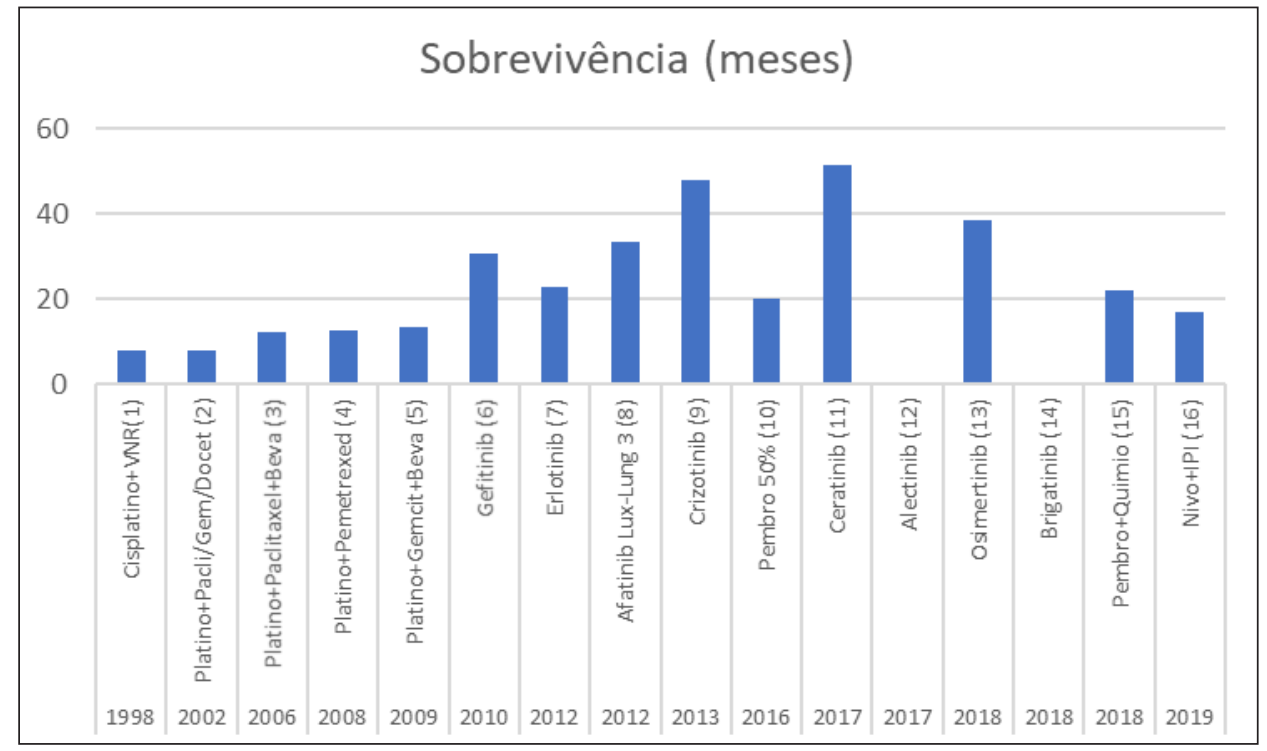

Referências: (1) Wozniak AJ, JCO 1998, (2) Schiller JA N Engl J 2002; (3) Sandler N Engl J 2006; (4) Scagliotti JCO 2008; (5) Martin Reck JCO 2009; (6) Maemondo N Engl J 2010; (7) Rosell Lancet 2012; (8) Yang JCO 2012; (9) Alice Shaw N Engl J 2013; (10)M Reck N Engl J 2016; (11) Soria N Lancet 2017; (12) Solange P N Engl J 2017; (13) Soria N Engl J 2017; (14) Camidge N Engl J 2018; (15) Gandhi N Engl J 2018; (16) Hellman N Engl J 2019

\section{BIBLIOGRAFIA}

1. Schiller JH, Harrington D, Belani CP, et al. Comparison of four chemotherapy regimens for advanced non-small-cell lung cancer. New Engl J Med. 2002; 346:92-8

2. Rapp E, Pater JL, Willan A, et al. Chemotherapy can prolong survival in patients with advanced, non-small-cell lung cancer - report of a Canadian multicenter randomized trial. J Clin Oncol. 1988; 6:633-41

3. Marino P, Pampallona S, Pretoni A, et al. Chemotherapy versus suppotive care in advanced non-small-cell lung cancer: results of meta-analysis of the literature. Chest 1994; 106:861$-5$

4. Grilli R, Oxman AD, Julian JA. Chemotherapy for advanced non-small cell lung cancer: how much benefit is enough? J Clin Oncol 1993;11: 1866-72.
5. Hespanhol V, Queiroga H, Magalhães A, et al. Survival Predictors in Non-Small Cell Lung Cancer. Lung Cancer 13 (1995); 253-267

6. Chemotherapy in non-small cell lung cancer: a meta-analysis using up-dated data on individual patients from 52 randomized clinical trials. BMJ 1995; 311:899-909

7. Bunn P.A. (1991) The Role of Systemic Chemotherapy in Non-Small Cell Lung Cancer. In: Bunn P.A. (eds) Current Topics in Lung Cancer. ESO Monographs (European School of Oncology). Springer, Berlin, Heidelberg. https://doi. org/10.1007/978-3-642-76784-5_5

8. Wozniak AJ, Crwley JJ, Balcerzak SP, et al. Randomized Trial Comparing Cisplatin With Cisplatin Plus Vinorelbine in the Treatment of Advanced Non-Small Cell Lung Cancer: A Southwest Oncologic Group Study. J Clin Oncol, 1998. 16:2459-2465 . 
9. Murray N. The importance of dose and dose intensity in lung cancer. Seminars in Oncology 1987, 14 (4, Suppl): 20-28

10. Foote M. The Importance of Planned dose of chemotherapy on Time: Do we need to Change Our clinical Practice? The Oncologist 1998; 3:365-368

11. Lyman GH. Impact of Chemotherapy Dose Intensiy on Cancer Patients. JNCCN 2009. 7: 99-108

12. Sheehan GR, Balaban EP, Frenkel EP. The impact of Dose Intensity of Standard Chemotherapy Regimens in Extensive Stage Small Cell Lung Cancer. Am J Clin Oncol 1993; 3: 250-255

13. Camps VC, Provencio M Isla $M$, et al. Cisplatin plus Gencitabine versus cisplatine based triplet versus non platin sequential doublets in advanced non-small-cell lung cancer: a Spanish Lung Cancer Group Phase III randomized trial J Clin Oncol Trip2003; 21:3207-3213

14. Boni C, Tiseo M, Boni M. et al. Triplets versus doublets, with or without cisplatin, in the first line treatment of stage IIIB-IV non-small cell lung cancer (NSCLC) patients: a multicenter randomized factorial trial (FAST). British Journal of Cancer 201; 106:658-665

15. Rossi A, Chiodini P, Barata F, et al. Six Versus Fewer Planned Cycles of First-Line Platinum-Based Chemotherapy for Non-Small-Cell Lung Cancer: A Systematic Review and Meta-Analysis of Individual Patient Data.. Lancet Oncology 2014; 11:1254-1262

16. Barata FJ, Parente B, Teixeira E, et al. Optimal duration of chemotherapy in non-small-cell lung cancer: multicenter, randomized, prospective clinical trial comparing 4 vs 6 cycles of carboplatin and gemcitabine. J Thorac Oncol 2007; 2 (suppl 4): S666 (abstr P2-235).

17. Peterson P, Park K, Fossella FV, et al. Is pemetrexed more effective in adenocarcinoma and large cell lung cancer than in squamous cell carcinoma? A retrospective analysis of a phase III trial of pemetrexed vs docetaxel in previously treated patients with advanced non-small cell lung cancer (NSCLC). 12th World Conference on Lung Cancer (Abstracts). J Thorac Oncol 2007;2: S851.

18. Hanna N, Shephard F, Fossella FV, et al. Randomized Phase III Trial of Pemetrexed Versus Do- cetaxel in Patients With Non-Small-Cell Lung Cancer Previously Treated With Chemotherapy. J Clin Oncol 2004. 22:1589-1597

19. Chena CY,b, Changc Y, Shiha JY, et al. Thymidylate synthase and dihydrofolate reductase expression in non-small cell lung carcinoma: The association with treatment efficacy of pemetrexed. Lung Cancer 74 (2011) 132- 138

20. Scagliotti GV, Parikh P, von Pawel, J, et al. Phase III Study Comparing Cisplatin Plus Gemcitabine With Cisplatin Plus Pemetrexed in Chemotherapy-Naive Patients With Advanced-Stage Non-Small-Cell Lung Cancer. Clin Oncol 2008. 26:3543-3551

21. Friedberg EC. How nucleotide excision repair protects against cancer. Nat rev Cancer 2001; 1:22-33

22. Olaussen KA, Dunant $A$, Fouret $P$ et al. DNA repair by ERCC1 in non-small-cell lung cancer and cisplatin-based adjuvant chemotherapy. N Engl J Med 2006; 355:983-91

23. Gadzar AF. DNA Repair and survival in Lung Cancer - The Two faces of Janus. N Engl J Med 2007; 356;8

24. Zheng Z, Chen T, Xueli L, et al. DNA Synthesis and repair Genes RRM1 and ERCC1 in Lung Cancer. N Engl J Med 2007; 356:800-8

25. Ceppi P, Volante M, Novello S, et al. ERCC1 and RRM1 gene expressions but not EGFR are predictive of shorter survival in advanced non-small-cell lung cancer. N Engl J Med 2006; 355:570-80

26. Shin DM Scagliotti G Kindler, et al. A pfase III trial of pemetrexed in malignant (MPM) patients: clinical outcome, role of vitamin supplementation, respiratory symptoms and lung function (abstract 1175). Proc Am Soc Clin Oncol 22:294a, 2002

27. Chen IC, Chang LY, Shih YJ, et al. Thymedilate synthase and dihydrifolate reductase expression in non-small-cell lung carcinoma: the association with treatment efficacy of pemetrexed. Lung Cancer 2011; 74:132-139

28. Ceppi P, Volante M, Saviozzi S, et al. Squamous cell carcinoma of the lung compared with other histotypes shows higher messenger RNA and protein levels for thymedylate synthase. Cancer 2006; 107: 1589-96

29. Shin DM Scagliotti G Kindler, et al. A pfase III trial of pemetrexed in malignant (MPM) patients: cli- 
nical outcome, role of vitamin supplementation, respiratory symptoms and lung function (abstract 1175). Proc Am Soc Clin Oncol 22:294a, 2002

30. Chabner BA, Koop E, Niederhuber JE, et al Homage to Judah Folkman. The Oncologist 2008; 13: 205-211

31. Folkman N. Clinical applications of research on angiogenesis. N Engl J Med 1995;333: 1757-63.

32. Herbst RS, Onn A, Sandler Alan. Angiogenesis and Lung Cancer: Prognostic and Therapeutic implications. J Clin Oncol 2005. 23: 3243-3256

33. Sandler A, Gray R, Perry MC, et al. Paclitaxel-Carboplatin Alone or with Bevacizumab for Non-Small-Cell Lung Cancer. N engl J Med 2006. 355:2542-50

34. Reck M, von Pawel J, Zatloukal P, et al. Phase III Trial of Cisplatin Plus Gemcitabine With Either Placebo or Bevacizumab As First Line therapy for Nonsquamous Non-Small-Cell Cancer: AVAil. J Clin Oncol 2009. 27:1227-1234

35. Reck M, Kaiser R, Mellemgaard A, et al. Docetaxel plus nintedanib versus docetaxel plus placebo in patients with previously treated non-small-cell lung cancer (LUME-Lung 1): a phase 3, double-blind, randomised controlled trial Lancet Oncol 2014.15:143-145

36. Hanna NH, Kaiser R, Sullivan R, et al. Nintedanib plus pemetrexed versus placebo plus pemetrexed in patients with relapse or refractory, advanced non small cell lung cancer (LUME-LUNG2): A randomized, double-blind, Phase III trial. Lung Cancer 2016. 102:65-73

37. Ciulleanu T, Brodowicz T, Zielinski C, et al. Maintenance pemetrexed plus best supportive care, versus placebo plus best supportive care for non-small-cell: a randomized double blind, phase 3 study. Lancet 2009; 14: 253-63

38. Paz-Ares L, Marinis F, Dediu M, et al. Maintenance therapy with pemetrexed plus best supportive care versus placebo plus best supportive care after induction therapy with pemetrexed plus cisplatin for advanced non-squamous non-small-cell lung cancer (PARAMOUNT): a double blind, phase 3, randomized controlled trial. Lancet Oncol 2012; 12: 247-55

39. Paz-Ares L, Marinis F, Dediu M, et al. PARAMOUNT: Final Overall Survival Results of the
Phase III Study of Maintenance Pemetrexed Versus Placebo Immediately After Induction treatment With Pemetrexed Plus Cisplatin for Advanced Nonsquamous Non-Small-Cell Lung Cancer. J Clin Oncol 2013; 31: 2895-2902

40. Azzoli CG, Baker S Jr, Temin S, et al. American Society of Clinical Oncology Clinical Practice Guideline update on chemotherapy for stage IV non-small-cell lung cancer. J Clin Oncol 2009; 27: 6251-66

41. Sandler A. Bevacizumab in non-small-cell lung cancer. Clin Cancer Res 2007; 13: s4613-16

42. Edwin F. et al. A Histological Perspective of EGF Receptor and related Systems. In: Patel T.B., Bertics PJ (eds) Epidermal Growth Factor. Methods in Molecular Biology, 2006; Vol 327. Humana Press

43. Hirsh FR, Varella GM, Bunn PD Jr, et al. Epidermal grow factor receptor non-Small-cell lung carcinomas: correlation between gene copy number and protein expression and impact on prognosis. J Clin Oncol 2003. 20: 3798-3807

44. Mendelshon J. Blockage og receptors for growth factors: an anticancer therapy-the fourth annual Joseph H Burchenal American Association for Cancer Research Clinical Research Award Lecture. Clin Cancer Research 2000; 6: 747-753

45. Druker BJ, Talpaz M, Resta DJ, et al. Efficacy and safety of specific inhibitor of BCL-ABL tyrosine kinase in chronic myeloid leukemia. New England J Med 2001; 344: 1031-37

46. Kris MG, Natale NB, Herbs RS, et al. Efficacy of gefitinib an inhibitor of Epidermal Growth Factor Receptor Tyrosine Kinase, in Symptomatic Patients of Non-Small-Cell Lung Cancer. JAMA 2003; 16: 2149-2158

47. Fukuoka M, Yano S, Giaccone J, et al. Multi-Institutional Randomized Phase II Trial of Gefitinib for Previously Treated Patients With Advanced Non-Small-Cell Lung Cancer 2003; 12:2237-42

48. Giaccone G, Herbst R, Manegold C, et al. Gefitinib in Combination With Gemcitabine and Cisplatin in Advanced Non-Small-Cell Lung Cancer: A Phase III Trial - INTACT 1. J Clin Oncol 2004; 22: 777-784

49. Herbst R, Giaccone G, Shiller JH, et al. Gefitinib in Combination With Paclitaxel and Carboplatin 
in Advanced Non-Small-Cell Lung Cancer: A Phase III Trial - INTACT 2. J Clin Oncol 2004; 22: 785-794

50. Gatzmeier U Pluzanska A, Szczesna A, et al. Results of phase III trial of Erlotinib combined with cisplatin and gemcitabine chemotherapy in non-small cell lung cancer. Proc Am Soc Clin Oncol. 2004; 23 (Abstract \#7010).:617

51. Herbst RS, Prager D Herman R, et al. Tribute: a phase III trial of Erlotinib $\mathrm{HCl}(\mathrm{OSI}-774)$ combined with carboplatin and paclitaxel (CP) in advanced non-small cell lung cancer. Proc Am Soc Clin Oncol. 2004; 23 (Abstract \#2000).:127

52. Lynch TJ, Bell DW, Sordella R, et al. Activating Mutations in the Epidermal Growth Factor Receptor Underlying Responsiveness of NonSmall-Cell Lung Cancer to Gefitinib. N Engl J Med 2004;350: 2129-39

53. Shepherd FA, Pereira JR, Ciuleani T, et al. Erlotinib in Peeviously Treated Non-Small-Cell Lung Cancer. N Engl J Med. 2005; 353; 123-132

54. Mok TS, Wu YL, Thongprasert S, et al. Gefitinib or Carboplatin-Paclitaxel in Pulmonary Adenocarcinoma. N Engl J Med 2009; 361: 947-957

55. Maemondo M, Inoue A, Kobayashi K. et al. Gefitinib or chemotherapy for non-small cell lung cancer with mutated EGFR. N Engl J Med 2010. 25:2380-8

56. Rosell R, Carcenery E, Gervais R., et al. Erlotinib versus standard chemotherapy as first line treatment for European patients with advanced EGFR mutation-positive non-small-cell lung cancer (EURTAC): a multicenter, open-label, randomized phase 3 trial. Lancet Oncol. 2012. 3:239-46

57. Sequist LV, Yang JC, Park K, et al. Phase III study of Afatinib or Cisplatin plus Pemetrexed in patients with metastatic lung adenocarcinoma with EGR mutations. J Clin Oncol 2013. 31:3327$-34$

58. Leon F, Golsorkhi A, Drozdowskyj A, et al. Overall Survival Analysis of First Line Erlotinib Versus Chemotherapy in the EURTAC Study Population Controlling for the Use of Post-Study Therapy. Annals of Oncology 2014; Suppl. 4page iv447

59. Yang JCH, Wu YL, Schuler M, et al. Afatinib versus cisplatin -based chemotherapy for EGFR mutation-positive lung adenocarcinoma (Lux-
-Lung 3 and Lux-Lung 6): analysus of overall survival data from two randomized, phase 3 trials. Lancet Oncol 2015. 16; 2: P141-151

60. Sholl ML, Aisner DL, Varella-Garcia M, et al. Multi-institutional Oncogenic Driver Mutation Analysis in Lung Adenocarcinoma The Lung Cancer Mutation Consortium Experience. J Thorac Oncol. 2015;10: 768-777

61. Reis D, Marques C, Dias M, et al. Mutational profile of non-small-cell lung cancer patients: Use of next generation sequencing Pulmonology 2019. Pulmonology 50-52

62. Pakkala S, Ramaligngam SS Personalized therapy for lung cancer:striking a moving target. $\mathrm{JCl}$ Insight. 2018. 3;15: 120858

63. Solomon BJ, Mok T, Kim DW, et al. First-Line Crizotinib versus Chemptherapy in Alk-Positive Lung Cancer. N engl J Med 2014; 371: 2167-2177

64. Shaw AT, I.Ou SH, Bang YJ, et al. Crizotinib in ROS1-Rearranged Non-Small-Cell Lung Cancer. N Engl J Med 2014. 371: 1963-1971

65. Waqar NS, Morgensztern D, Sehn J, et al. Met Mutation Associated with Responsiveness to Crizotinib. J Thoracic Oncol 2015; 5: e29-e31

66. Carper MB, Claudio PP. Clinical potential of gene mutations in lung cancer. Clin Transl Med 2015. 4: 33

67. Marino FZ, Bianco R, Accardo M, et al. 200Molecular heterogeneity in lung cancer: from mechanisms of origin to clinical implications. Int $\mathrm{J}$ Med Sci 2019. 16:; 7:981-989

68. Villalobos $P$, Wistuba II. Lung Cancer Biomarkers. Hematol Oncol clin North Am. 2017. 31; 1: 13-29

69. Hanahan D and Weinberg RA. Hallmarks of Cancer Cell 2000. 100; 7: 57-70

70. Hanahan D and Weinberg RA. Hallmarks of Cancer Cell 2011. 144; 4: 646-674

71. Aparicio $S$, Caldas $C$. The implications of clonal Genome Evolution for Cancer Medicine. N Engl J Med 2013; 368: 842-51

72. Jia $Q$, Wu W, Wang Y. et al. Local mutational diversity drives intratumoral immune heterogeneity in non-small cell lung cancer. Nature Communications 2018. 9:5361

73. Mitsudomi T Morita S, Yatabe $Y$, et al. Gefitinib versus cisplatin plus docetaxel in patients with non-small-cell lung cancer harbouring mutsations 
of epidermal grow factor receptor: an open label, randomized phase 3 trial. Lancet Oncol 2010; 118; 2:121-128

74. Mitsudomi T Morita S, Yatabe Y, et al. Gefitinib versus cisplatin plus docetaxel in patients with non-small-cell lung cancer harbouring mutsations of epidermal grow factor receptor: an open label, randomized phase 3 trial. Lancet Oncol 2010; 118; 2:121-128

75. Mitsudomi T Morita S, Yatabe Y, et al. Gefitinib versus cisplatin plus docetaxel in patients with non-small-cell lung cancer harbouring mutsations of epidermal grow factor receptor: an open label, randomized phase 3 trial. Lancet Oncol 2010; 118; 2:121-128

76. Van Assche K, Ferdinande L, Lievens $Y$ et al. EGFR mutation positive stage IV non-small cell lung cancer: treatment beyond progression. Front Oncol 2014; 4:350

77. Weickhardt AJ, Scheier B, Burke JM, et al. Local ablative therapy of oligoprogressive disease prolongs disease control by tyrosine kinase inhibitors in oncogene-addicted non-small-cell- lung cancer. J Thorac Oncol 2012. 7; 12: 1807-18014

78. Yu HA, Arcila ME, Rekhtman N et al. Analysis of tumor specimens at the time of acquired resistance to EGFR-TKI therapy in 155 patients with EGFR-mutant lung cancers. Clin Cancer Res 2013. 19; 8: 2240-2247

79. Jann PA, Yang JC-H, Kim D-W et al. AZD9291 in EGFR inhibitor-resistant non-small-cell lung cancer. N Engl J Med 2015. 372; 18:1689-1699

80. Gross G, Tsai CM, Sheferd FA, et al. Osimertinib for pretreated EGFR Thr790MET-positiveadvanced non-small-cell lung cancer (AURA2): a multicentre, open label, single arm, phase 2 study. Lancet Oncol 2016; doi: 10.1016/S1470-2045; 16: 30508-3

81. Soria JC, Ohe Y, Vansteenkiste J, et al. Osimertinib in Untreated EGFR-Mutated advanced Non-Small-Cell Lung Cancer. N Eng J Med 2018. 378 : 113-125

82. Ramalingam SS, Vansteenkist J, Planchard D, et al. Overall survival with Osimertinib in untreated, EGFR-Mutated Advanced NSCLC. N Engl J Med 2020. 382: 41-50

83. Ricordel C, Friboulet L, Facchinetti F et al. Molecular mechanisms of acquired resistance to third- -generation EGFR-TKIs in EGFR T790m-mutant lung cancer. Annals of Oncology 2018; 29 (Supplement 1) i28-i37

84. Camidge R, Po W, Sequist LV. Acquired Resistance to TKIs in solid tumours: learning from lung cancer. Nat Rev Clin Oncol 2014; 11: 473-481

85. Making the first move in EGFR-driven or ALK-driven NSCLC: first generation or next generation TKIs? Nat Rev Clin Oncol 2018;

86. Schaw AT, Kim TM, Crinó L, et al. Ceratinib versus chemotherapy in patients with alk-rearranged non-small-cell- lung cancer previously given chemotherapy and crizotinib (ASCEND-5): a randomized, controlled, open-label, phase 3 trial. The Lancet Oncology 2017. 18; 7: 874-886

87. Peters S, Camidge R, Shaw AT, et al. Alectinib versus Crizotinib in Untreated ALK-Positive NonSmall-Cell Lung Cancer. N Engl J Med 2017. 377: 829-38

88. Hida $T$, Nokihara $H$, Kondo $M$, et al. Alectinib versus crizotinib in patients with ALK-positive non-small-cell lung cancer (J-ALEX): an open-label, randomised phase 3 trial. The Lancet 2017. 390; 10089: 29-39

89. Huber RM, Hansen KH, Paz-Ares L, et al. Brigatinib in Crizotinib-Refractory AIK+ NSCLC: 2-Year Follow-up on Systemic and intrcraneal Outcomes in Phase 2 ALTA Trial. J Thorac Oncol 2020. 15; 3: 405-415

90. Camidge DR, Kim HR, Ahn MJ, et al. Brigatinib versus Crizotinib in ALK-Positive Non-Small-Cell Lung Cancer. New Engl J Med 2018. 379: 2027-39

91. Gaynor JF, Dardaei L, Yoda S, et al. Molecular Mechanisms of Resistance of First and Second-Generation ALK Inhibitors in ALK Rearranged Lung Cancer. Cancer Discovery 2026. 6; 10: 1118-1133

92. Solomon BJ, Besse B, Bauer TM, et al. Lorlatinib in patients with ALK-positive non-small-cell lung cancer: results from a global phase 2 study. Lancet Oncol 2018. 19; 12: 1654-1667

93. Lin JJ, Zhu VW, Yoda S. Impact of EML4-ALK Variant on Resistance Mechanisms and Clinical Outcomes in ALK-Positive Lung Cancer. J Clin Oncol 2018. 36: 1199-1206

94. Ribas A Releasing the Brakes on Cancer Immunotherapy. N Engl J Med 2015; 373;16: 1490-92 
95. Pardoll D. The blockade of immne checkpoints in cancer immunotherapy. Nature 2012. 12:252-264

96. Zou W, Chen L. Inhibitory B7-family molecules in the tumor microenvironment. Nature Rev. Immunol. 2008. 8; 467-477

97. Rizvi NA, Mazieres J Planchard D, et al. Activity and safety of nivolumab um anti-PD1 immune check point inhibitor, for patients with advanced, refractory squamous non-small-cell lungcancer (Check Mate 063): a phase 2, single arm trial. Lancet Oncol, 2015; 16:257-265

98. Borghaei H, Paz-Ares L, Horn L, et al. Nivolumab versus Docetaxel in Advanced Nonsquamous Non-Small-Cell Lung Cancer. N Engl J Med 2015; 373:1627-1639

99. Garon EB, Rizvi NA, Hui R, et al. Pembrolizumab for the treatment of non-small-cell lung cancer. $N$ Engl Med. 2015; 372:2018-2028.

100. Reck M, Abreu DR, Robinson AG, et al. Pembrolizumab versus Chemotherapy for PD L1 Positive Non-Small-Cell Lung Cancer. N Engl J Med 2016; 375:1823-1833

101

102. Reck M, Abreu DR, Robinson AG, et al. Pembrolizumab versus Chemotherapy for PD L1 Positive
Non-Small-Cell Lung Cancer. N Engl J Med 2016; 375:1823-1833

103. Rizvi AN, Hellmann HD, Snyder A, et al. Mutational landscape determines sensitivity to PD-1 blockade in non-small cell lung cancer. Science. 2015 April 3; 348(6230): 124-128

104. Katsurada M, Nagano T, Tachihara M, et al. Anticancer Research 2019. 39: 815-825 (2019)

105. Warth A, Cortis J, Soltermann A, et al. Tumour cell proliferation (Ki-67) in non-small cell lung cancer: a critical reappraisal of its prognostic role. British Journal of Cancer 2014. 111: 1222-1229

106. Gandhi L, Rodríguez-Abreu D, Gadgeel S, et al. Pembrolizumab plus Chemotherapy in Metastatic Non-Small-Cell Lung Cancer. N Engl J Med 2018; 378:2078-92

107. M.D. Hellmann, T.-E. Ciuleanu, A. Pluzanski, et al. Nivolumab plus Ipilimumab in Lung Cancer with a High Tumor Mutational Burden. N Engl J Med 2019; 381:2020-2031

108. Socinsk MA, Jotte RM, Cappuzzo F, et al. Atezolizumab for First-Line Treatment of Metastatic Nonsquamous NSCLC. N Engl J Med 2018;378: 2288-301 